\title{
Clinical Profile of Obstetric Patients Getting Admitted to ICU in a Tertiary Care Center Having HDU Facility: A Retrospective Analysis
}

\author{
Soumya Ranjan Panda ${ }^{1} \cdot$ Madhu Jain ${ }^{1} \cdot$ Shuchi Jain ${ }^{1}$
}

Received: 18 October 2017/Accepted: 25 November 2017/Published online: 21 December 2017

(C) Federation of Obstetric \& Gynecological Societies of India 2017

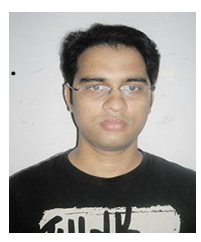

\begin{abstract}
About the Author
Soumya Ranjan Panda He has passed his MS (Obstetrics and Gynecology) from VSS MCH, Burla, Odisha, in 2014. At present, he is a senior resident in the Department of Obstetrics and Gynecology, IMS, BHU, Varanasi
\end{abstract}

\begin{abstract}
Background The critically ill obstetric patient represents a challenge that usually requires a multidisciplinary approach. Lack of awareness and the absence of regular antenatal care make the critically ill patients to be referred late and sometimes in moribund conditions. The objective of the present study is to determine the incidence, predictors and outcome of obstetric ICU admissions.

Methods This retrospective study was conducted over a period of 2 year from July 2015 to June 2017 in
\end{abstract}

Soumya Ranjan Panda is a Senior Resident in the Department of Obstetrics and Gynecology at IMS, BHU, Varanasi. Madhu Jain is a Professor and Head in the Department of Obstetrics and Gynecology at IMS, BHU, Varanasi, Shuchi Jain is a Assistant Professor in the Department of Obstetrics and Gynecology at IMS, BHU, Varanasi.

Madhu Jain

drmadhu4141@gmail.com

1 Department of Obstetrics and Gynecology, IMS, BHU, Varanasi, India
Department of Obstetrics and Gynecology at Institute of Medical Sciences, BHU, Varanasi, India.

Results Out of a total of 4986 deliveries, 756 patients underwent HDU admission, while 92 obstetric patients were admitted to ICU during this study period. Maximum number of patients $(73.91 \%)$ were in the age-group of 20-35 years, $64.13 \%$ of patients constitute lower socioeconomic status group, $68.47 \%$ of patients reside in rural area and there was inadequacy in receiving antenatal care in case of $60.86 \%$ of patients. Maximum number of patients were admitted for a period of 4-7 days. Blood transfusion (64.1\%), the use of inotropic drugs (45.6\%), central line placement $(44.5 \%)$ and mechanical ventilation (26.08\%) were the major interventions performed in ICU. Obstetric hemorrhage was found to be the most frequent clinical diagnosis leading to ICU admission (31.5\%) followed by hypertensive disorders $(25 \%)$.

Conclusion In addition to timely referral, health education and training of health professionals may improve clinical outcome and better obstetric practice, especially in 
countries like India. Obstetric ICU dedicated for the management of only obstetric patients should be constructed in order to compensate for heavy burden critically ill women.

Keywords Obstetric ICU · HDU · Maternal mortality

\section{Introduction}

Pregnancy is a special physiological condition in a woman's life but sometimes could have detrimental effect to the extent of severe maternal morbidity or mortality. The critically ill obstetric patient represents a challenge that usually requires a multidisciplinary approach. Lack of awareness and the absence of regular antenatal care make the critically ill patients to be referred late and sometimes in moribund conditions. In order to provide them specialized care and reduce maternal mortality and morbidity, specialized obstetric intensive care units and high dependency units need to be established. Evaluation of obstetric admissions to intensive care unit (ICU) is one of the ways to approach surveillance of critically ill women in pregnancy in a tertiary care facility [1]. Data from developed countries show an ICU admission rate of $0.1-1.7 \%$ [2].

\section{Objective}

The objective of the present study is to determine the incidence, predictors and outcome of obstetric ICU admissions.

\section{Materials and Method}

This retrospective study was conducted over a period of 2 year from July 2015 to June 2017 in Department of Obstetrics and Gynecology at Institute of Medical Sciences, BHU, Varanasi, India. It is a tertiary care center getting referrals not only from nearby cities and hospitals but also from major cities of neighbor states like eastern Uttar Pradesh, Bihar and Madhya Pradesh. It has one 16-bedded ICU with facilities for intubation, ventilation, CVP monitoring and establishment of arterial lines. During this time frame, a total of 4986 deliveries have taken place, 756 women were admitted to HDU, while 92 cases were admitted to ICU.

Data were collected from previous hospital records. All pregnant women admitted to the hospital (antenatal and postnatal up to 6 weeks) were included in the study. The number of above women who needed ICU admission was noted. The demographic details, indications for ICU admission, any inadequacy of antenatal care, comorbidities, obstetric features (antepartum history, gestational age, antenatal abnormalities, mode of delivery, vital signs and other pregnancy complications) were noted on admission to the ICU. The causes of admission to ICU were classified as obstetric and non-obstetric causes. Obstetric disorders were defined as pregnancy-related condition which occurred during pregnancy or within 42-days postpartum period. Non-obstetric conditions were defined as other medical or surgical conditions that were not pregnancy related. For each patient, data pertaining to ICU interventions like mechanical ventilation, the use of blood and blood products, the use of inotropes, anticonvulsants and antihypertensives were noted. ICU scoring system like APACHE and SAPS was not used as the obstetric patients are relatively young and physiological alterations during

Table 1 HDU and ICU admissions

\begin{tabular}{lcc}
\hline & No. of patients & Rate of admission \\
\hline Total obstetric admission & 4986 & \\
HDU admission & 756 & $15.16 \%$ \\
ICU admission & 92 & $1.84 \%$ \\
\hline
\end{tabular}

Table 2 Demographic parameters of patients admitted to ICU and HDU

\begin{tabular}{|c|c|c|}
\hline Age-group & No. of cases admitted to ICU & Percentage $(\%)$ \\
\hline$<20$ & 9 & 9.78 \\
\hline $20-35$ & 68 & 73.91 \\
\hline$>35$ & 15 & 16.31 \\
\hline \multicolumn{3}{|c|}{ Socioeconomic status } \\
\hline Lower & 59 & 64.13 \\
\hline Middle & 28 & 30.45 \\
\hline Higher & 5 & 5.42 \\
\hline \multicolumn{3}{|c|}{ Residential area } \\
\hline Rural & 63 & 68.47 \\
\hline Urban & 29 & 31.53 \\
\hline \multicolumn{3}{|c|}{ Antenatal care } \\
\hline Adequate & 36 & 39.14 \\
\hline Inadequate & 56 & 60.86 \\
\hline \multicolumn{3}{|c|}{ Duration of delay (h) } \\
\hline$<1$ & 12 & 13.04 \\
\hline $1-12$ & 32 & 34.79 \\
\hline$>12$ & 48 & 52.17 \\
\hline \multicolumn{3}{|c|}{ Organ system affected } \\
\hline Single & 5 & 5.42 \\
\hline Multi & 87 & 94.58 \\
\hline
\end{tabular}

Most of the women (94.58\%) were having multiorgan dysfunction 
Table 3 Criteria for transfer of patients to ICU

\begin{tabular}{|c|c|c|}
\hline Organ system & Criteria & $\begin{array}{l}\text { No. of } \\
\text { cases }\end{array}$ \\
\hline Respiratory arrest & $\begin{array}{l}\text { Respiratory rate }>40 \text { or }<8 \text { breaths } / \text { min } \\
\text { Oxygen saturation }<90 \% \text { on } \geq 50 \% \text { oxygen }\end{array}$ & 29 \\
\hline Cardiac arrest & $\begin{array}{l}\text { Pulse rate }<40 \text { or }>140 \text { beats per min } \\
\text { Systolic } \mathrm{BP}<90 \mathrm{~mm} \text { of } \mathrm{HG}\end{array}$ & 26 \\
\hline CNS derangement & $\begin{array}{l}\text { Sudden fall in level of consciousness (fall in Glasgow Coma Scale }>2 \text { points) } \\
\text { Repeated or prolonged seizures } \\
\text { Absent gag or cough reflex } \\
\text { Raised intracranial pressure requiring treatment } \\
\text { Hypoxemia } \\
\text { Hypercapnia or hypocapnia } \\
\text { Rising arterial carbon dioxide tension with respiratory acidosis }\end{array}$ & 19 \\
\hline $\begin{array}{l}\text { Signs suggestive of diminished tissue } \\
\text { perfusion }\end{array}$ & $\begin{array}{l}\text { Tachycardia } \\
\text { Confusion or diminished consciousness level } \\
\text { Poor peripheral perfusion (cool, cyanosed extremities, poor capillary refill, poor } \\
\quad \text { peripheral pulses) } \\
\text { Poor urine output } \\
\text { Metabolic acidosis } \\
\text { Increased blood lactate concentrations }\end{array}$ & 27 \\
\hline Renal derangement & $\begin{array}{l}\text { Oliguria }(<0.5 \mathrm{ml} / \mathrm{kg} / \mathrm{h}) \\
\text { Life-threatening hyperkalemia }(>6 \mathrm{mmol} / \mathrm{l}) \text { resistant to drug treatment } \\
\text { Rising plasma concentration of urea or creatinine or both } \\
\text { Severe metabolic acidosis } \\
\text { Symptoms related to uremia }\end{array}$ & 14 \\
\hline Liver derangement & $\begin{array}{l}\text { Clinical and laboratory features of DIC } \\
\text { Signs and symptoms of hepatic encephalopathy }\end{array}$ & 9 \\
\hline
\end{tabular}

Table 4 Interventions undertaken in obstetric ICU

\begin{tabular}{lll}
\hline Interventions & No. of cases & Percentage $(\%)$ \\
\hline Blood transfusion & 59 & 64.1 \\
Central line & 41 & 44.5 \\
Inotropic drugs & 42 & 45.6 \\
Anticonvulsant drugs & 18 & 19.5 \\
Antihypertensives & 17 & 18.4 \\
Dialysis & 12 & 13.04 \\
Mechanical ventilator & 24 & 26.08 \\
\hline
\end{tabular}

pregnancy can cause false higher scores because of any pathology.

\section{Results}

Table 1 shows out of a total of 4986 deliveries 756 patients underwent HDU admission, while 92 obstetric patients were admitted to ICU during this study period. Table 2 shows the demographic parameters of patients being admitted to ICU. Maximum number of patients $(73.91 \%)$ were in the age-group of 20-35 years, $64.13 \%$ of patients constitute lower socioeconomic status group, $68.47 \%$ of patients reside in rural area, and there was inadequacy in receiving antenatal care in case of $60.86 \%$ of patients. There was a delay in seeking treatment and getting admitted to ICU for most of the patients. We found a delay of $>12 \mathrm{~h}$ of duration in case of $52.17 \%$ of patients. Maximum number of patients were admitted for a period of 4-7 days as evidenced in Table 3. Blood transfusion $(64.1 \%)$, the use of inotropic drugs $(45.6 \%)$, central line placement $(44.5 \%)$ and mechanical ventilation $(26.08 \%)$ were the major interventions performed in ICU (Table 4). As depicted in Table 5, obstetric hemorrhage was found to be the most frequent clinical diagnosis leading to ICU admission (31.5\%) followed by hypertensive disorders (25\%). Non-obstetric disorders contribute to about $18.4 \%$ of ICU admission. A total of $32(34.78 \%)$ maternal mortalities were noted among all ICU admissions. Out of 32 deaths, $24(75 \%)$ were among the group of women 
Table 5 Indications for admission and mortality in ICU

\begin{tabular}{|c|c|c|c|c|c|c|}
\hline \multicolumn{7}{|c|}{ Admission to ICU $(N=92)$} \\
\hline \multicolumn{3}{|c|}{ Medical indication (21/92) } & \multicolumn{4}{|l|}{ Obstetric indication (71/92) } \\
\hline $\begin{array}{l}\text { Medical indication } \\
(21 / 92)\end{array}$ & $\begin{array}{l}\text { No. of } \\
\text { cases }\end{array}$ & $\begin{array}{l}\text { Mortality } \\
(N=8)\end{array}$ & Obstetric indication (71/92) & & No. of cases & $\begin{array}{l}\text { Mortality } \\
(N=24)\end{array}$ \\
\hline Cardiac disease & $10 \quad(10.86 \%)$ & 2 & Obstetric hemorrhage $(44.56 \%)$ & $\mathrm{PPH}$ & $19(20.65 \%)$ & 7 \\
\hline Severe anemia & $3(3.26 \%)$ & 1 & & Placenta previa & $5(5.42 \%)$ & 2 \\
\hline Pulmonary edema & $8(8.68 \%)$ & 3 & & Placenta accreta & $4(4.34 \%)$ & 2 \\
\hline ARDS & $4(4.34 \%)$ & 2 & & Ruptured ectopic & $6(6.52 \%)$ & 1 \\
\hline $\mathrm{ARF}$ & $7(7.6 \%)$ & 2 & & Ruptured uterus & $6(6.52 \%)$ & 2 \\
\hline Hepatic disease & $3(3.26 \%)$ & 2 & & Molar pregnancy & $1(1.08 \%)$ & Nil \\
\hline $\begin{array}{l}\text { Non-obstetric } \\
\text { sepsis }\end{array}$ & $1(1.08 \%)$ & Nil & $\begin{array}{c}\text { Hypertensive disorders of } \\
\text { pregnancy }(27.17 \%)\end{array}$ & Eclampsia/severe preeclampsia & $19(20.65 \%)$ & 5 \\
\hline Epilepsy & $4(4.34 \%)$ & Nil & & HELLP syndrome & $6(6.52 \%)$ & 2 \\
\hline \multirow[t]{2}{*}{ Diabetes } & $6(6.52 \%)$ & Nil & Sepsis $(17.39 \%)$ & $\begin{array}{l}\text { Puerperal sepsis/septic } \\
\text { abortion/septic shock }\end{array}$ & $16(17.39 \%)$ & 3 \\
\hline & & & Others & Obstructed labor & $4(4.32 \%)$ & Nil \\
\hline
\end{tabular}

admitted for obstetric causes, and $8(25 \%)$ were among those admitted for non-obstetric causes.

\section{Discussion}

In the present study, out of total obstetric admissions to hospital, $1.84 \%$ were admitted to ICU. Some reports from previous studies show an ICU admission rate that ranges from 0.1 to $1.7 \%$ [2-5], while other studies show an admission rate of $3.3 \%$ [6]. Similarly, HDU admission rate in our institute was found to be $15.16 \%$. HDU constitutes an intermediate level of care between general ward and ICU. It involves triage of patients and step-up or step-down support between ward and ICU. However, procedures such as intubation with mechanical ventilation for advanced respiratory support, invasive investigations and monitoring (beyond central venous and long arterial lines) or multiple organ support are usually not the remit of HDU. In fact, the presence of a HDU can reduce the number of ICU admissions by $53 \%$, thus making ICU beds available to more needy women well in time [4].

Table 2 depicts that those women from lower to middle socioeconomic status, from rural areas of residency and having inadequate antenatal care comprise the major bulk of patients that got admitted to ICU. Most of these women are unbooked for antenatal visit. Previous studies also have reported that unbooked women may have more complications, resulting in an increased need for ICU care [7]. Involvement of more than one organ systems was seen in $94.58 \%$ women. The reason for such high percentage of women with multiorgan dysfunction among ICU admissions is the fact that most of the women with single-organ system involvement are being managed in the HDU available in our institute. This is very high in comparison with previous studies where more than one organ system was involved in around $20 \%$ cases [8]. This reflects on to the poor health status of our women and the advanced stage of disease by the time they reach ICU. Criteria for the transfer of patients to ICU have been described in Table 4. Most of the patients were having multiorgan dysfunction.

Obstetric complications accounted for the majority of ICU admissions ( $n=75,81.6 \%)$ as compared to non-obstetric conditions $(n=17,18.4 \%)$. Previous studies $[9,10]$ also reported obstetric complications to be a major cause of admission to ICU. As depicted in Table 5, obstetric hemorrhage was found to be the most frequent clinical diagnosis leading to ICU admission (31.5\%) followed by hypertensive disorders (25\%). Also worse prognosis was seen with hemorrhagic disorders with the mortality of around $37.93 \%$ as compared to $28 \%$ in hypertensive disorders. Hemorrhagic complications constituted greater danger to life of affected woman reflecting need for aggressive treatment. Similar results were seen in other studies from the literature [11].

The incidence of mortality in cases admitted to ICU was $34.78 \%$ which is higher than reported $15-20 \%$ from other developing countries [12]. However, a study conducted in New Delhi reported a similarly high mortality rate of $40 \%$ [13]. Increased maternal mortality rates reported have been attributed to treatment by quacks, low socioeconomic status, poor antenatal care, low hematocrit and undernutrition of obstetric patients [14]. 
Most common intervention in ICU was the need for oxygen and blood transfusion along with intensive monitoring and care of patient. Authors from other parts of the world also observed that hemodynamic and respiratory complications needing inotropic or ventilatory support remain the most important reasons for ICU admissions, and the need for support may predict poor outcome $[9,12]$.

Very few women could present to health facility without any delay. Study conducted by Bajwa et al. in Banur, India, also found poor transport facilities, poor rural health infrastructure, customs and traditions of local community to be contributing toward an increased ICU admission [15].

\section{Conclusion}

The most common reasons for ICU admission in this study were obstetric hemorrhage, hypertension and its complications. A lot of issues need be addressed at different levels of patient care. A multidisciplinary team approach is appropriate in obstetric critical care settings. In addition to timely referral, health education and training of health professionals may improve clinical outcome and better obstetric practice, especially in countries like India. Establishment of functional HDU may help in earlier admission of critically ill patients for better observation. It may also reduce the burden of admissions to ICU, as HDU can be used for the observation of patients not fit for ward observation. Awareness should be created among the population regarding the importance of adequate antenatal care, detection of danger signs of various obstetric complications and need for contacting medical facilities in case of emergency situations. Obstetric ICU dedicated for the management of only obstetric patients should be constructed in order to compensate for heavy burden critically ill women.

\section{Compliance with Ethical Standards}

Conflict of interest The authors declare that they have no competing interests.

Ethical approval This article does not contain any study involving human participants or animal performed by any of the authors, as it's a retrospective analysis from the hospital records.

Informed consent We have obtained the required informed consents.

\section{References}

1. Richa F, Karim N, Yazbeck P. Obstetric admissions to the intensive care unit: an eight-year review. J Med Liban. 2008;56:215-9.

2. Basket TF. Epidemiology of obstetric critical care. Best Prac Res Clin Obstet. 2008;22(5):763-74.

3. Goffman D, Madden RC, Harrison EA, et al. Predictors of maternal mortality and near-miss maternal morbidity. J Perinatol. 2007;27:597-601.

4. Okafor UV, Efetie ER. Critical care obstetrics in a developing country. J Turk Ger Gynecol Assoc. 2008;9:9-13.

5. Jain S, Guleria K, Vaid NB, et al. Predictors and outcome of obstetric admissions to intensive care unit: a comparative study. Indian J Public Health. 2016;60:159-63.

6. Monsalve GA, Martínez CM, Gallo T, et al. Maternal critical care: outcomes and patient characteristics in a combined obstetric high dependency unit in Medellín, Colombia. Rev Colomb Anestesiol. 2011;39(2):190-205.

7. Verma D, Rathore AM. Obstetric admission to the ICU unit of a tertiary hospital in northern India. Int $\mathrm{J}$ Biomed Res. 2014;05(09):539-42.

8. Oliveira-Neto A, Parpinelli MA, Cecatti JG, et al. Sequential organ failure assessment score for evaluating organ failure and outcome of severe maternal morbidity in obstetric intensive care. Sci World J. 2012;2012:172145.

9. Ramachandra Bhat PB, Navada MH, Rao SV, et al. Evaluation of obstetric admissions to intensive care unit of a tertiary referral centre of coastal India. Indian J Crit Care Med. 2013;17(1):34-7.

10. Vasquez DN, Estenssoro E, Canales HS, et al. Clinical characteristics and outcomes of obstetric patients requiring ICU admission. Chest. 2007;131:718-24.

11. Pérez A, Acevedo O, Tamayo Fdel C, et al. Characterization of obstetric patients with multiple organ failure in the intensive care unit of a Havana teaching hospital, 1998 to 2006. MEDICC Rev. 2010;12:27-32.

12. Leung NY, Lau AC, Chan KK, et al. Clinical characteristics and outcomes of obstetric patients admitted to the intensive care unit: a 10-year retrospective review. Hong Kong Med J. 2010;16:18-25.

13. Tempe A, Wadhwa L, Gupta S, et al. Prediction of mortality and morbidity by simplified acute physiology score II in obstetric intensive care unit admissions. Indian $\mathrm{J}$ Med Sci. 2007;61:179-85.

14. Gupta S, Naithani U, Doshi V, et al. Obstetric critical care: a prospective analysis of clinical characteristics, predictability and fetomaternal outcome in a new dedicated obstetric intensive care unit. Indian J Anaesth. 2011;55:146-53.

15. Bajwa SK, Bajwa SJ, Kaur J, et al. Is intensive care the only answer for high risk pregnancies in developing nations? J Emerg Trauma Shock. 2010;3:331-6. 